\title{
Caminhos da Política Nacional de Formação de Professores na Modalidade a Distância
}

\author{
Camila Silva Sousa Santos ${ }^{1}$, Gilda Helena Bernardino de Campos²
}

\begin{abstract}
1 Mestre em Educação Brasileira e Membro do Grupo de Pesquisa Cooperação e Avaliação em Educação a Distância, Departamento de Educação da Pontifícia Universidade Católica do Rio de Janeiro (PUC-Rio). Rua Marquês de São Vicente, 225, ed. Padre Leonel Franca, 20 andar, Gávea - Rio de Janeiro- RJ - Brasil. camilasousasantos01@gmail.com

2 Professora Doutora do Departamento de Educação, Coordenadora da Educação a Distância e Coordenadora do Grupo de Pesquisa Cooperação e Avaliação em Educação a Distância da Pontifícia Universidade Católica do Rio de Janeiro (PUC-Rio). Rua Marquês de São Vicente, 225, ed. Padre Leonel Franca, 20 andar, GáveaRio de Janeiro - RJ - Brasil. gilda@ccead.puc-rio.br
\end{abstract}

\section{Resumo}

Este artigo tem por objetivo examinar os caminhos percorridos pelas políticas públicas de formação de professores na modalidade a distância, através da rede pública de educação superior, a partir de três seções: a escolha do Estado brasileiro pela modalidade a distância na formação inicial e continuada de professores, apoiando-se em Kingdon (2007) para explicitar a eleição de tal política; a criação da UAB e a formação de professores como sinônimo de democratização do acesso ao ensino superior brasileiro pela rede pública de educação a distância (EaD); e a escolha da Capes para a operacionalização das políticas de formação de professores no país. O trabalho teve como procedimento metodológico a análise documental de leis e decretos que nos levaram a afirmar que as políticas nacionais de formação docente, através da UAB e da Parfor, movimentaram a EaD da periferia para o centro das políticas do MEC e, desde 2009, buscam novos caminhos com a operacionalização pela Nova Capes.

Palavras-chave: Políticas de formação de professores; UAB; Nova Capes. 


\title{
Paths of National Teacher Education Policy in Distance \\ Learning Mode
}

\begin{abstract}
This paper aims to examine public policies related to teacher's formation in distance learning courses in three areas: the Brazilian state choice for undergraduate and continuing education for teachers, based in Kingdon (2007) to explain this selection; the creation of the Brazilian Open University - UAB - and teacher's formation as a synonym for democratization of distance learning education; and the election of CAPES to operate these policies. As for methodology, this work has made use of documental analyzes of laws and decrees, and it can be concluded that, through UAB and PARFOR, the national policies for teacher's formation have put distance learning education in the centre of the Ministry of Education agenda and since 2009 have been searching for new ways to operate with the New CAPES.
\end{abstract}

Keywords: Public policies related to teacher's formation; Brazilian Open University UAB; New CAPES. 


\section{Introdução}

No cenário educacional atual, não é mais possível deslocar a educação a distância (EaD) da expansão da educação superior brasileira, bem como das políticas públicas de formação inicial e continuada de professores no país. Tais políticas se articulam diretamente com a qualidade da educação básica, na medida em que a expansão da educação superior tem se tornado sinônimo de formação de professores e esta última tem demandado, cada vez mais, uma estrutura que possibilite a esses professores a aquisição de maior competência pedagógica e responsabilidade com as escolas. Essa nova estrutura vislumbra uma gestão mais democrática e menos centralizada, maior capacidade de trabalhar de forma ativa, coletiva e participativa, compreendendo as novas competências necessárias para a sociedade atual e buscando caminhos para que a escola se torne uma instituição social cada vez mais autônoma e potente.

É trivial ressaltar que a profissão docente é uma das principais funções e peçachave no desenvolvimento das sociedades modernas, pois o seu exercício é central no contexto cultural, político e econômico das nações, tendo em vista que a escolarização continua sendo a principal forma de socialização e formação das sociedades modernas ocidentais. Sendo assim, ser professor, no contexto societário atual, demanda formação prolongada, de alto nível e em conformidade com o exercício pleno da função docente.

Segundo Gatti, Barreto e André (2011), o mundo contemporâneo apresenta novos ordenamentos estruturais e novas demandas e pressões. Nesse contexto, a preocupação com a educação e com a formação de professores e suas condições de trabalho são questões importantes para a sociedade, na medida em que precisamos de professores que assumam o compromisso de uma escola mais justa, que dê sentido à maioria das demandas de cidadania, sobretudo entre as camadas mais empobrecidas.

Por essa razão, neste artigo, discutiremos como a EaD se tornou uma questão de deliberação enquanto política pública de formação inicial e continuada de professores. Para tanto, apresentaremos algumas razões políticas pelas quais o Estado brasileiro dedicou sua atenção a esse caminho, como se constituiu essa agenda ${ }^{1}$ e como essa escolha foi filtrada a partir de um repertório de alternativas existentes.

Segundo Kingdon (2007, p.221),

a formulação de políticas públicas é um conjunto de processos, incluindo pelo menos: o estabelecimento de uma agenda; a especificidade das 
alternativas a partir das quais as escolhas são feitas; uma escolha final entre essas alternativas específicas, por meio de votação no Legislativo ou decisão presidencial; e a implementação dessa decisão.

\section{Metodologia}

Como procedimento metodológico, optamos pela análise documental de leis e decretos de políticas públicas nacionais de educação, buscando descrever a forma como tais documentos moldaram as políticas públicas atuais e compreender em que medida os seus textos convergiam a partir de três temáticas: (1) políticas públicas nacionais de formação de professores; (2) expansão e democratização da universidade pública brasileira; e (3) implementação da EaD como modalidade de ensino. Para tanto, utilizamos os seguintes documentos: Lei de Diretrizes e Bases da Educação Nacional (LDBEN, Lei no 9.394, de 20 de dezembro de 1996); Plano Nacional de Educação (PNE, Lei no 10.172, de 9 de janeiro de 2001); Universidade Aberta do Brasil - UAB (Decreto no 5.800, de 8 de junho de 2006); Nova Capes (Lei no 11.502, de 11 de julho de 2007);

e Política Nacional de Formação de Profissionais do Magistério da Educação Básica Parfor (Decreto nº 6.755, de 29 de janeiro de 2009).

Optamos, ainda, pela priorização de dados da década de 1990 e primeira década de 2000, com o intuito de reconstruir o cenário em que tais documentos foram forjados. Assim, pudemos compreender quais caminhos delinearam a política nacional de formação de professores na modalidade a distância tal como é conhecida no panorama brasileiro atual, entendendo que eles se inserem em uma perspectiva política e social.

\section{Resultados e Discussão}

A constituição da agenda e o filtro das alternativas começaram a se constituir ainda na década de 1990, a partir de três demandas geradas pela LDBEN/1996: a universalização do ensino fundamental (artigo $4^{\circ}$ ), a formação docente em nível superior, nas licenciaturas (artigo 63) e o desenvolvimento e a veiculação de programas de ensino a distância (artigo 80). No início da década de 2000, com a aprovação do PNE/2001, outras demandas se somaram a essas já existentes: oferta de educação superior para, pelo menos, 30\% dos jovens na faixa etária entre 18 e 24 anos até o final do ano de 2010 e o estabelecimento de um amplo sistema interativo de educação a distância, utilizando-o, inclusive, para ampliar as possibilidades de atendimento nos 
cursos presenciais, regulares ou de educação continuada (Metas 1 e 4 da seção Educação Superior); oferta de cursos a distância, em nível superior, especialmente na área de formação de professores para a educação básica e ampliação gradual para todas as áreas em nível superior, incentivando a participação das universidades e das demais instituições de educação superior credenciadas (Metas 11 e 12 da seção Educação a Distância e Tecnologias Educacionais).

Segundo Mota, Filho e Cassiano (2006), em 2004, apenas 10,5\% da população brasileira tinham acesso ao ensino superior. Na educação superior pública, concentravase a parcela da população com maior renda, revelando uma forte desigualdade de acesso ao ensino superior dos menos favorecidos economicamente. A parcela mais pobre da população, em razão de suas necessidades objetivas, abandonava os estudos ainda no ensino fundamental ou ao final do ensino médio para ingressar no mercado de trabalho. As instituições de ensino superior público se concentravam nos centros urbanos e capitais, concentrando a oferta de vagas em cerca de $30 \%$ dos municípios.

Quanto à formação docente, o que se constatou é que a formação dos professores nos primeiros anos da década de 2000 era um ponto nevrálgico na implantação de políticas públicas. Segundo o Censo Escolar/Inep de 2005, 38,1\% dos docentes brasileiros em exercício atuavam sem a licenciatura completa. Em termos regionais, esses dados se agravavam pela assimetria entre as regiões brasileiras: nas regiões Norte e Nordeste, 55\% dos docentes não possuíam licenciatura e nas regiões Sul, Sudeste e Centro-Oeste, esse número girava em torno de $28 \%$. Dessa forma, a associação do nível de formação docente com a qualidade da educação básica foi praticamente imediata e essa constatação foi suficiente para se perceber a urgência de se traçarem políticas de formação inicial e continuada de qualidade para esses professores que já atuavam ou viriam a atuar na educação básica. Sendo assim, a democratização da educação superior demandava, inicialmente, uma educação básica de qualidade que impulsionasse a expansão do ensino superior e a formação de professores representava uma peça-chave nesse processo (Mota, Filho \& Cassiano, 2006).

Diante da leitura do cenário político e social do Brasil no início da década de 2000 e da interpretação desse cenário à luz das demandas geradas pela LDBEN/1996 e pelo PNE/2001, é possível inferir que os possíveis temas ou problemas com base nos quais os governantes poderiam constituir a sua agenda estavam postos. Era preciso: (1) formar professores em nível superior (licenciatura), em quantidade e com qualidade, 
capazes de absorver a demanda da universalização do ensino fundamental, em curso desde a LDBEN/1996, e impulsionar a demanda de expansão do ensino superior, gerada pelo PNE/2001; (2) democratizar o ensino superior, contornando a pobreza da maioria da população brasileira e a desigualdade de ofertas regionais; e (3) desenvolver e veicular programas de EaD, conforme propunha a LDBEN/1996 e corroborou o $\mathrm{PNE} / 2001$, sobretudo voltados para a formação de professores.

Segundo Kingdon (2007), é a partir dos temas e problemas que estão na agenda que um conjunto de alternativas começa a ser seriamente considerado pelas autoridades governamentais e por pessoas estreitamente associadas a elas. Em outras palavras, as alternativas passam a ser consideradas com base nos processos de problemas, no fluxo da política e de participantes. As situações são reconhecidas e tomadas como problemas por comparação com o que ocorre em outros países ou com outras unidades relevantes. Então, uma vez que a situação é avaliada como problema, algumas abordagens e alternativas são enfatizadas, em detrimento de outras e, nesse processo, os participantes envolvidos devem fazer com que as pessoas responsáveis pelas decisões enxerguem o problema e as alternativas da mesma forma que eles.

Alguns autores (Oliveira, 2009; Ferreira, 2010; Lopes \& Pereira, 2011; Souza \& Moraes, 2013) enfatizam que as diretrizes, recomendações e condicionalidades dos organismos internacionais, tais como a Unesco e o Banco Mundial, representam grande influência nas políticas de formação docente através da modalidade EaD implantadas no Brasil nos últimos anos. Contudo, Leher (2010) nos alerta para o fato de que muitos estudos caem no erro de buscar correlações imediatas e lineares entre as medidas de um dado governo e as referidas diretrizes, desconsiderando que estas são recontextualizadas em virtude de dimensões históricas, conceituais e correlações de forças.

Os processos de constituição da agenda e disposição das alternativas não ocorrem organizadamente, em estágios, passos ou fases; são dinâmicos, independentes e fluem pelo sistema todos ao mesmo tempo. Assim, não há uma relação linear entre a percepção de um problema e uma proposição de alternativa, podendo ocorrer de a alternativa já ter sido definida e defendida pelos participantes e, a partir dela, surgir a definição da agenda. Kingdon (2007) nos propõe que vejamos o surgimento de alternativas para políticas públicas como um processo de seleção natural: muitas alternativas surgirão, mas serão consideradas apenas as que apresentarem maior força política, dentro de um 
cenário político nacional mais amplo, o que inclui viabilidade técnica, aceitação por parte dos participantes da política e a antecipação de possíveis restrições, como orçamento, aceitabilidade do público e receptividade dos políticos.

Sendo assim, a formação de professores através da EaD emerge como política pública nacional dada a sua potencialidade de: (1) capilarizar e interiorizar a educação superior pública, expandindo e democratizando o número de vagas nas instituições governamentais de ensino superior; (2) oferecer formação inicial e continuada a professores em exercício, respeitando a sua demanda e horários de trabalho, dada a flexibilidade dos horários desse tipo de curso, além de responder pela demanda de formação de novos docentes para atuar nas redes públicas de ensino; (3) permitir o acesso a cursos de formação superior às camadas da população que não conseguiriam estar neles de forma presencial e que, em geral, são as camadas mais pobres da população; (4) incentivar, através da formação em nível superior, o desenvolvimento de municípios localizados em regiões distantes e isoladas.

Na década de 2000, o Brasil já dispunha, em certa medida, de viabilidade técnica para a implantação e o uso de tecnologias da informação e comunicação em processos formativos de educação. Os participantes da política pareciam concordar com as propostas já colocadas, sobretudo em relação à democratização da educação superior pública, ao uso de tecnologias e à formação docente em nível superior. O orçamento disponível, a aceitabilidade do público e a receptividade dos políticos acenavam de forma positiva para tal deliberação, tendo em vista que, naquele momento, parecia inviável conceber alternativas melhores para os temas e problemas propostos na agenda. Dessa forma, a política de formação docente em nível superior através da modalidade de educação a distância parecia ser uma ideia que havia atingido o seu momento.

Em 8 de junho de 2006 foi criado, por meio do Decreto no 5.800, o Sistema Universidade Aberta do Brasil (UAB), "voltado para o desenvolvimento da modalidade a distância, com a finalidade de expandir e interiorizar a oferta de cursos e programas de educação superior no País." (Brasil, 2006). Seus objetivos propõem soluções de ordem social, política e econômica, partindo de uma política de formação docente e capacitação de gestores e profissionais da educação básica e de democratização da universidade pública. Essa democratização ocorreria através da ampliação do número de vagas, da distribuição mais equânime da oferta de educação superior entre as regiões brasileiras e do estabelecimento da modalidade a distância como sistema nacional de educação 
superior, bem como de seu desenvolvimento institucional e metodológico ancorado em pesquisas e em tecnologias da informação e comunicação. Dessa forma, é possível inferir que, no âmbito do Sistema UAB, a democratização da educação superior pública se tornaria sinônimo de política nacional de formação de professores.

Do ponto de vista legal, o artigo 80 da LDBEN/1996 já preconizava e oferecia o aval para que a modalidade de educação a distância se estabelecesse como programa de ensino credenciado e regulamentado pela União. Também o PNE/2001 corroborou para que a EaD se constituísse como principal estratégia de operacionalização de uma política nacional de formação de professores. Em 2006, ano de criação da UAB, as bases para a expansão e a regulação da educação a distância já estavam postas, ainda que sua regulação tenha vindo a posteriori da expansão dessa modalidade. Torna-se central compreender que o Sistema UAB retirou a EaD da periferia das políticas públicas educacionais do Ministério da Educação (MEC) e a transportou, a partir das políticas de formação docente, para o centro das ações desse ministério, conforme nos informa Segenreich (2013).

Em 2006, a EaD já dispunha de um ato regulatório que instituía, de forma precisa, a sua regulação e caracterização como modelo de EaD semipresencial ancorada na presença da figura do tutor. Esse ato regulatório trata-se do Decreto no 5.622, de 19 de dezembro de 2005. No período compreendido entre 2001 e 2003, as universidades públicas participavam majoritariamente da oferta de EaD no Brasil, embora a comunidade acadêmica mostrasse resistência à modalidade. Após esse período, o que se percebe é que a oferta de EaD no Brasil torna-se majoritária pela rede privada, conforme mostram os dados oficiais (Brasil, 2013).

Foram precursores do Sistema UAB alguns programas, projetos e ações exitosos, desenvolvidos no âmbito dos estados e municípios, em parceria com o MEC, tendo como objetivo melhorar a educação básica a partir da formação inicial e continuada de professores e de gestores. É o caso da Secretaria de Educação a Distância (Seed), criada em 1996 e que, ainda que não tratasse da educação superior, era um canal de discussão da modalidade presente em uma secretaria ministerial. No âmbito dessa secretaria foram gestados os projetos TV Escola e Programa Nacional de Tecnologia Educacional (ProInfo), programas que projetaram a Seed no cenário internacional da EaD e do uso de novas tecnologias educacionais, garantindo, em certa medida, uma estrutura governamental favorável para que essa modalidade se desenvolvesse. 
A Associação Brasileira de Educação a Distância (Abed), criada em 1995, tem um papel fundamental nesse processo, apoiando, incentivando, estimulando, promovendo e fomentando a prática, o aperfeiçoamento, a pesquisa, o uso de tecnologias educacionais e o espírito criativo e democrático da EaD. A presença da UniRede (Universidade Virtual Pública do Brasil), criada em 1999 e reunindo 70 instituições de educação superior (IES) federais e estaduais dispostas a fazer EaD, também foi fundamental para que uma rede de intenções se encaminhasse para o projeto da UAB.

Há, ainda, o curso de Pedagogia a distância da Universidade Federal do Mato Grosso, realizado em consórcio com o governo estadual do Mato Grosso e com a Universidade Estadual do Mato Grosso, que, criado em 1995, tinha por objetivo oferecer formação inicial e continuada para professores em exercício nas redes públicas de ensino; o consórcio Centro de Educação a Distância do Estado do Rio de Janeiro (Cederj), de 2000, que inicialmente se concentrou nas licenciaturas e depois se abriu para outras áreas de formação; o projeto Veredas, criado em 2002 em Minas Gerais, também em consórcio com o governo estadual e várias IES desse estado, cujo objetivo era, também, formar professores das séries iniciais das escolas públicas, através de cursos a distância; além do projeto-piloto do curso de administração do Banco do Brasil, de 2006.

O Pró-Licenciatura I, de 2003, fruto de uma parceria entre o MEC - sob a responsabilidade da Secretaria de Educação Superior, a Seed - e a UniRede, tinha por objetivo chamar as universidades públicas para o desenvolvimento de cursos de graduação a distância. Esse programa se concretizou com a publicação de um edital de chamada pública endereçado às IES públicas, que apresentaram 21 projetos, sendo aprovados 19, organizados em 16 grupos de universidades, envolvendo 34 IES e aprovando 17.565 vagas. Em 2004, foi lançado o edital para o Pró-Licenciatura II e 72 IES responderam à chamada, esboçando mais de 170 projetos de cursos, abrangendo o Brasil inteiro e sinalizando a exequibilidade do projeto (Franco, 2006).

Todos esses fatores geraram um cenário que contribuiu para a criação do Sistema UAB como política pública nacional de expansão da educação superior pública e formação de professores através da modalidade a distância. Segundo Clímaco e Siqueira (2013), em 2013, o Sistema UAB era

Integrado por 103 IPES, sendo 56 universidades federais, 30 estaduais e 17 Institutos Federais de Educação, Ciência e Tecnologia, além de 645 polos de apoio presencial ativos - centros de formação em localidades estratégicas em todas as unidades da federação, onde os alunos e 
professores dos cursos a distância realizam as atividades presenciais indispensáveis aos projetos pedagógicos, incluindo as avaliações. Estão em andamento 923 cursos de EaD, dos quais 371 de graduação e 552 de pósgraduação lato sensu, com aproximadamente 270 mil matrículas, sendo $52,5 \%$ de licenciatura. De acordo com o EducaCenso 2001, há mais de 70 mil professores em serviço nas redes públicas de educação básica matriculados no sistema. Nos diversos níveis, contam-se mais de 42 mil concluintes na UAB.

A partir de 2009, o Sistema UAB passou a ser operacionalizado pela Coordenação de Aperfeiçoamento de Pessoal de Nível Superior (Capes), o que pode significar a abertura de novos caminhos e possibilidades para a formação de professores na modalidade EaD. Criada em 11 de julho de 1951, pelo Decreto no 29.741, a Capes tinha por objetivo "assegurar a existência de pessoal especializado em quantidade e qualidade suficientes para atender às necessidades dos empreendimentos públicos e privados que visam ao desenvolvimento do país." (BRASIL, 1951). Segundo Clímaco e Siqueira (2013), a idealização do seu primeiro dirigente, o educador Anísio Teixeira, era que a Capes pudesse cuidar da formação de pessoal em todos os níveis de ensino, o que não aconteceu até 2007. Em 56 anos de história, esse órgão se dedicou, quase que exclusivamente, ao fomento e à avaliação do Sistema Nacional de Pós-Graduação do país.

A partir de 2007, a "Nova Capes" começa a realizar o sonho de Anísio Teixeira, por meio da Lei no 11.502, de 11 de julho de 2007, que modificou as competências e a estrutura organizacional do órgão. Segundo o texto dessa lei, em seu artigo $2^{\circ}$ :

\begin{abstract}
No âmbito da educação básica, a CAPES terá como finalidade induzir e fomentar, inclusive em regime de colaboração com os Estados, os Municípios e o Distrito Federal e exclusivamente mediante convênios com instituições de ensino superior públicas ou privadas, a formação inicial e continuada de profissionais de magistério, respeitada a liberdade acadêmica das instituições conveniadas, observado, ainda, o seguinte: I na formação inicial de profissionais do magistério, dar-se-á preferência ao ensino presencial, conjugado com o uso de recursos e tecnologias de educação a distância; II - na formação continuada de profissionais do magistério, utilizar-se-ão, especialmente, recursos e tecnologias de educação a distância (Brasil, 2007).
\end{abstract}

Em 29 de janeiro de 2009, é instituída, por meio do Decreto no 6.755, a Política Nacional de Formação de Profissionais do Magistério da Educação Básica (Parfor) com a finalidade de organizar, em regime de colaboração entre a União, os Estados, o Distrito 
Federal e os municípios, a formação inicial e continuada dos profissionais do magistério para as redes públicas da educação básica (artigo $1^{\circ}$ ). Esse mesmo decreto disciplina a atuação da Capes no fomento a programas de formação inicial e continuada de professores, bem como a responsabiliza pelos requisitos, condições de participação e critérios de seleção de instituições e de projetos pedagógicos específicos a serem apoiados (artigo $7^{\circ}$ ).

Passados pouco mais de dois meses, em 2 de abril de 2009, a Capes recebeu do MEC, por meio da portaria no 318, a responsabilidade pela operacionalização do Sistema UAB. Segundo o texto do então ministro Fernando Haddad,

considerando a necessidade e a conveniência de articular a Política Nacional de Formação de Profissionais do Magistério da Educação Básica ao Sistema Universidade Aberta do Brasil - UAB, bem como de disciplinar a formação de professores para a educação básica conforme parâmetros nacionais, (BRASIL, 2009b).

Essa portaria resolvia que o Sistema UAB seria operacionalizado pela Capes (artigo 10) e que a Seed forneceria à coordenação todos os dados, informações e recursos materiais e humanos necessários ao cumprimento do disposto no artigo $1^{\circ}$. Segundo Clímaco e Siqueira (2013), o objetivo dessa medida era:

conferir à modalidade Educação a Distância (EaD), no nível superior, o reconhecimento angariado, no País e no exterior, pelo Sistema Nacional de Pós-graduação, em especial no incremento da formação inicial e continuada de professores da educação básica.

Em janeiro de 2011, o MEC anunciou a extinção da Seed e a transferência de seus programas e projetos para a Secretaria de Educação Básica e de Educação Superior. Essa decisão dividiu opiniões dos especialistas acerca do lugar da EaD nas políticas públicas educacionais. Segundo Moran (apud Fernandes, 2011):

Extinguir a secretaria foi prematuro e aumentou o risco da modalidade ficar em segundo plano [...] A lógica é entrar em uma normalidade, contemplando os mesmos instrumentos para as modalidades a distância e presencial. Porém, dependendo de como esse processo seja feito, a educação a distância corre o risco de não ser prioridade tendo em vista as outras demandas do MEC. 
Litto (2011) pondera que:

Por um lado, a extinção da SEED é um sinal de que a EAD caminha para se tornar parte integrante do processo educacional como um todo, e não como uma modalidade isolada deles, o que é bom e justo. Por outro lado, precisa-se ressaltar que ainda estamos afetados por um processo de "consolidação regulatória" da EAD no Brasil. Vem sendo desenvolvido, desde 2007, um trabalho estruturante encaminhado pela SEED, que provavelmente será continuado no âmbito da nova Secretaria de Regulação. [...] Queremos garantir, assim, que as centenas de milhares de alunos que buscam sua formação por meio da EAD possam ter efetividade na sua aprendizagem e formação adequada.

Parece-nos que ainda é cedo para discutirmos os resultados da presença e centralidade da "Nova Capes" na operacionalização das políticas educacionais de formação de professores, tanto na modalidade de educação a distância como na presencial, e que a compreensão mais adequada acerca do papel dessa coordenação nessas políticas demanda pesquisas. O que podemos inferir, a partir dos documentos apresentados e analisados, é que o MEC tem concentrado os seus esforços, partindo da atuação da "Nova Capes" em criar políticas de formação de professores mais orgânicas e unitárias, não distinguindo ou isolando modalidades e compreendendo todos os níveis de ensino. O que evidencia tal percepção é a extinção da Seed e a presença do princípio de regime de colaboração entre a União, os Estados, o Distrito Federal e os municípios, no texto de lei que modificou as competências e a estrutura organizacional dessa coordenação, que institui a UAB e a Parfor. O uso de recursos e tecnologias de educação a distância também figura comumente nos três documentos, bem como a necessidade de integração de todos os níveis de ensino da educação pública.

\section{Considerações Finais}

Neste artigo, evidenciamos, com base na análise de documentos legais, que, a partir da década de 1990, uma série de determinações legais e acontecimentos iniciaram o caminho pelo qual a formação de professores na EaD se tornou uma ideia que atingiu o seu momento para acontecer no Brasil. Razões políticas convergiram e conduziram o Estado brasileiro a julgar e eleger, em meio a um repertório de alternativas existentes, esse caminho como sendo o mais adequado e, assim, constituiu-se uma agenda que articulou políticas de formação docente, democratização da educação superior pública e o desenvolvimento e veiculação do uso de tecnologias em processos formativos. Tais 
políticas ganharam centralidade nas políticas educacionais do MEC, com a instituição do Sistema UAB e novas possibilidades de caminhos, com a operacionalização da "Nova Capes", moldando, assim, as políticas públicas de educação atuais.

É importante salientar que, historicamente, até a promulgação da LDBEN/1996, a EaD no Brasil se caracterizou por ações e estratégias emergenciais que buscavam soluções para questões sociais graves, tais como o analfabetismo e a formação docente, mas que não mantinham continuidade. A partir da década de 2000, como apresentamos, a modalidade ganha uma nova dimensão na política educacional, com ambiciosos objetivos, diretrizes e metas de implementação. Segundo Gatti e Barreto (2009), no ano de 2002, acreditava-se que a EaD seria a iniciativa de maior alcance a fazer face à demanda de ampliação e democratização da educação superior e formação docente.

O evidente interesse do poder público pela ampliação da educação a distância, a partir da década de 2000, fez crescer, de forma acelerada e expressiva, o número de cursos e matrículas nessa modalidade. Gatti e Barreto (2009) evidenciam que, de 2000 a 2007, o número de cursos de graduação a distância, bem como o número de matrículas nessa modalidade cresceu cerca de oito vezes, ao passo que o número de vagas oferecidas por vestibulares e outros processos seletivos conseguiu ser 62 vezes maior em relação ao ano de 2002. Tais números se devem à adoção da política de EaD pelas universidades públicas e pela equiparação legal de cursos de graduação a distância aos presenciais. Nesse mesmo período, os cursos de licenciatura a distância se multiplicaram em quase seis vezes e o número de matrículas dobrou.

Em 2002, as universidades públicas concentravam cerca de $85 \%$ das matrículas (Gatti \& Barreto, 2009), o que parecia uma resposta às demandas que estavam postas acerca da democratização da educação superior pública e formação docente em nível superior. No entanto, esse cenário já se modificou bastante nos últimos anos e, em 2012, o setor privado já dominava $83,7 \%$ das matrículas e 55,5\% dos cursos na modalidade a distância (Brasil, 2014).

Por ora, é possível afirmarmos que, mesmo com todos os esforços apreendidos e aqui demonstrados, a complexidade das questões apresentadas neste artigo, no que tange à democratização da educação superior, formação de professores e difusão da modalidade EaD, não se esgota, pois reflete a intrínseca relação entre exclusão educacional e exclusão econômica e social brasileira. Contudo, há avanços que podem ser percebidos em meio a tantos desafios e assimetrias, tais como o aumento da taxa 
bruta de acesso ao ensino fundamental e à educação superior, embora a taxa do número de matrículas no ensino médio tenha se apresentado estável nos últimos anos, conforme mostram dados do Censo Escolar de 2014². Essa estabilidade, que vai na contramão do aumento da taxa de acesso ao ensino fundamental, sugere que o cenário apresentado no início da década de 2000 permanece: os jovens mais pobres, entre 18 e 24 anos, abandonam os estudos nesse nível de ensino ou o concluem e logo ingressam no mercado de trabalho. Essa razão pode ser apresentada, assim, como uma das possíveis explicações para o não atingimento da Meta 1 do PNE de 2001. Segundo o Censo da Educação Superior (Brasil, 2014), em 2011, a população brasileira apresentava 22.497.453 jovens na faixa etária compreendida entre 18 e 24 anos, mas apenas $14,59 \%$ destes (3.283.368 jovens) frequentavam cursos de graduação, o que representava menos da metade da meta proposta pelo PNE uma década antes. Deles, 3.229.755 frequentavam cursos presenciais, ao passo que 53.613 frequentavam graduação na modalidade a distância (EaD).

O aumento da taxa bruta de acesso ao ensino fundamental demandou que um número cada vez maior de professores fosse formado em nível superior, conforme determinação legal da LDBEN/1996. Sendo assim, não é por acaso que a ampliação do número de matrículas na educação superior tenha relação direta com a ampliação de vagas nas licenciaturas, sobretudo em cursos de graduação na modalidade a distância.

O estudo realizado por Gatti e Barreto (2009) demonstrou que o cenário da formação docente vem se modificado desde a segunda metade da década de 2000 e, em 2007, a maioria dos professores brasileiros possuía formação condizente com o nível de ensino em que trabalhava. Entre os docentes que atuavam na educação infantil e no ensino fundamental, mais de $95 \%$ possuíam formação em nível médio ou superior. A assimetria regional também diminuíra, embora ainda existisse: cerca de $15 \%$ dos professores que, no Nordeste, atuavam no segundo segmento do ensino fundamental (60 ao $9^{\circ}$ ano) ainda não possuíam nível superior completo, ao passo que nas regiões Sul e Sudeste, esses valores eram quase inexpressivos.

Sendo assim, é possível afirmarmos que as determinações legais apresentadas neste artigo moldaram um cenário de demandas que levou o Estado brasileiro a traçar políticas que convergissem, de modo a equacionar os desafios já apresentados. Como possibilidade de trabalhos futuros, resta-nos a inquietação acerca da expressa indução da ampliação da oferta de EaD pelo setor público, sendo suplantada pela atuação do 
setor privado, e a discussão acerca da formação de professores no Brasil. Observamos que, com a operacionalização da "Nova Capes", ela começa a se desprender da modalidade a distância e se pautar pela unidade e organicidade de políticas que compreendem que todos os níveis de ensino são complementares e devem fazer uso de recursos e tecnologias de EaD como forma de melhorar a qualidade da educação nacional.

\section{Agradecimentos}

Este artigo é parte de uma dissertação de Mestrado defendida em 15 de abril de 2015 no Departamento de Educação do Programa de Pós-Graduação em Educação da PUC-Rio e, por essa razão, agradecemos à Capes e à PUC-Rio pelos auxílios concedidos, sem os quais este trabalho não poderia ter sido realizado.

\section{Notas}

${ }^{1}$ Estamos concebendo agenda como uma "lista de temas e problemas que são alvo em dado momento de séria atenção, tanto por parte das autoridades governamentais como de pessoas fora do governo, mas estreitamente associada às autoridades." (Kingdon, 2007, p.222).

2 Fonte:

http://download.inep.gov.br/educacao basica/censo escolar/apresentacao/2014/apres entacao coletiva censo edu basica 022014.pdf

\section{Referências Bibliográficas}

Brasil (1951). Decreto no 29.741, de 11 de Julho de 1951. Institui uma Comissão para promover a Campanha Nacional de Aperfeiçoamento de pessoal de nível superior. Rio de Janeiro: Presidência da República. Disponível em http://www2.camara.leg.br/legin/fed/decret/1950-1959/decreto-29741-11julho-1951-336144-publicacaooriginal-1-pe.html 
Brasil (1996). Lei n 9.394, de 20 de dezembro de 1996. Estabelece as diretrizes e bases da educação nacional. Brasília: Presidência da República. Disponível em http://www.planalto.gov.br/ccivil 03/leis/l9394.htm

Brasil (2005). Decreto n 5.622, de 19 de dezembro de 2005. Regulamenta o art. 80 da Lei no 9.394, de 20 de dezembro de 1996, que estabelece as diretrizes e bases da educação nacional. Brasília: Presidência da República. Disponível em http://www.uab.CAPES.gov.br/images/stories/downloads/legislacao/decreto5622 . .pdf

Brasil (2006). Decreto $\mathrm{n}^{\circ}$ 5.800, de 08 de junho de 2006. Dispõe sobre o Sistema Universidade Aberta do Brasil - UAB. Brasília: Presidência da República. Disponível em

http://www.uab.CAPES.gov.br/images/stories/downloads/legislacao/decreto5800 . .pdf

Brasil (2007). Lei $n^{\circ} 11.502$, de 11 de julho de 2007. Modifica as competências e a estrutura organizacional da fundação Coordenação de Aperfeiçoamento de Pessoal de Nível Superior - Capes, de que trata a Lei $n^{\circ} 8.405$, de 9 de janeiro de 1992; e altera as Leis nos 8.405, de 9 de janeiro de 1992, e 11.273, de 6 de fevereiro de 2006, que autoriza a concessão de bolsas de estudo e de pesquisa a participantes de programas de formação inicial e continuada de professores para a educação básica. Brasília: Presidência da República. Disponível em http://www.planalto.gov.br/ccivil 03/ Ato2007-2010/2007/Lei/L11502.htm

Brasil (2009a). Decreto $n^{\circ}$ 6.755, de 29 de janeiro de 2009. Institui a Política Nacional de Formação de Profissionais do Magistério da Educação Básica, disciplina a atuação da Coordenação de Aperfeiçoamento de Pessoal de Nível Superior - Capes no fomento a programas de formação inicial e continuada, e dá outras providências. Brasília: Presidência da República. Disponível em http://www.planalto.gov.br/ccivil 03/ ato2007-2010/2009/decreto/d6755.htm

Brasil (2009b). Portaria $n^{\circ}$ 318, de 02 de abril de 2009. Dispõe sobre a transferência da Coordenação de Aperfeiçoamento de Pessoal de Nível Superior - CAPES a operacionalização do Sistema Universidade Aberta do Brasil - UAB. Brasília: Ministério da Educação. Disponível em 
http://www.uab.capes.gov.br/index.php/legislacao-uab/18-portarias/143portaria-nd-318-de-2-de-abril-de-2009

Brasil (2013). Ministério da Educação. Sinopse da educação superior 2012: graduação. Brasília: Instituto Nacional de Estudos e Pesquisas Educacionais Anísio Teixeira. Disponível em http://portal.inep.gov.br/superior-censosuperior-sinopse

Brasil (2014). Ministério da Educação. Censo da educação superior 2012: resumo técnico. Brasília: Instituto Nacional de Estudos e Pesquisas Educacionais Anísio Teixeira.

Disponível em

http://download.inep.gov.br/download/superior/censo/2012/

Clímaco, J. C. T. de S., \& Siqueira, M. B. (2013). CAPES quer integrar educação presencial e a distância. Estadão. Acesso em 6 de junho de 2014, disponível em http://educacao.estadao.com.br/noticias/geral,artigo-CAPES-quer-integrareducacao-presencial-e-a-distancia,1026219

Fernandes, S. (2011). Extinção da Secretaria de Educação a Distância no MEC é prematura, avalia especialista. Acesso em 6 de junho de 2014, disponível em http://portal.aprendiz.uol.com.br/2011/07/19/extincao-da-secretaria-deeducacao-a-distancia-no-mec-e-prematura-avalia-especialista/

Ferreira, S. (2010). Reforma da educação superior no Brasil e na Europa: em debate novos papéis sociais para as universidades. In XXXIII Reunião Anual da ANPEd, no GT Política do Ensino Superior. Caxambu.

Franco, S. R. K. (2006). O programa Pró-Licenciatura: gênese, construção e perspectivas. In Brasil. Ministério da Educação. Desafios da educação a distância na formação de professores (pp. 27-37). Brasília: Secretaria de Educação a Distância.

Gatti, B. A., \& Barreto., E. S. de S. (2009). Professores do Brasil: impasses e desafios. Brasília: Unesco. Disponível em http://unesdoc.unesco.org/images/0018/001846/184682por.pdf

Gatti, B. A., Barreto, E. S. de S., \& André, M. E. D. de A. (2011). Políticas docentes no Brasil: um estado da arte. Brasília: Unesco. 
Kingdon, J. W. (2007). Como chega a hora de uma ideia? In E. Saravia \& E. Ferrarezi. Políticas públicas: coletânea - volume 1 (pp. 219-246). Brasília: Enap.

Leher, R. (2010). Educação no governo de Lula da Silva: a ruptura que não aconteceu. In Os anos Lula: contribuições para um balanço crítico 2003-2010 (pp. 369-412). Rio de Janeiro: Garamond.

Litto, F. M. (2011). A visão da ABED sobre a extinção da SEED-MEC. Acesso em 6 de junho de 2014, disponível em http://www.abed.org.br/site/pt/midiateca/noticias ead/460/2011/02/a visao d a abed sobre a extincao da seed mec

Lopes, L. F., \& Pereira, M. de F. R. (2011). Formação de professores a distância: princípios orientadores. In XXXIV Reunião Anual da ANPEd, no GT Formação de Professores. Natal.

Mota, R., Filho, H. C., \& Cassiano, W. S. (2006). Universidade aberta do Brasil: democratização do acesso à educação superior pela rede pública de educação a distância. In Brasil. Ministério da Educação. Desafios da educação a distância na formação de professores (pp. 13-26). Brasília: Secretaria de Educação a Distância.

Oliveira, D. M. (2009). Educação a distância e formação de professores em nível superior no Brasil. In XXXII Reunião Anual da ANPEd, no GT Política do Ensino Superior. Caxambu.

Segenreich, S. C. D. (2013). Relação Estado e Sociedade na oferta e regulação da graduação a distância no Brasil: da periferia ao centro das políticas públicas. In S. C. D. Segenreich \& S. B. V. Bustamante (Orgs.). Políticas e práticas da Educação a Distância (EaD) no Brasil: entrelaçando pesquisas (pp. 23-47). Rio de Janeiro: Letra Capital.

Souza, R. A., \& Moraes, R. de A. (2013). Políticas públicas de formação por meio da educação a distância: o PROFORMAÇÃO e o PROGESTÃO. In XXXVI Reunião Anual da ANPEd, no GT Estado e Política Educacional. Goiânia. 